\title{
Imaging Brain Oxygenation with MRI Using Blood Oxygenation Approaches: Methods, Validation, and Clinical Applications
}

\author{
T. Christen, D.S. Bolar, and G. Zaharchuk
}

\begin{abstract}
SUMMARY: In many pathophysiologic situations, including brain neoplasms, neurodegenerative disease, and chronic and acute ischemia, an imbalance exists between oxygen tissue consumption and delivery. Furthermore, oxygenation changes following a stress challenge, such as with carbogen gas or acetazolamide, can yield information about cerebrovascular reactivity. The unique sensitivity of the BOLD effect to the presence of deoxyhemoglobin has led to its widespread use in the field of cognitive neurosciences. However, the high spatial and temporal resolution afforded by BOLD imaging does not need to be limited to the study of healthy brains. While the complex relationship between the MR imaging signal and tissue oxygenation hinders a direct approach, many different methods have been developed during the past decade to obtain specific oxygenation measurements. These include qBOLD, phase- and susceptibility-based imaging, and intravascular T2-based approaches. The aim of this review is to give an overview of the theoretic basis of these methods as well as their application to measure oxygenation in both healthy subjects and those with disease.
\end{abstract}

ABBREVIATIONS: $\mathrm{BOLD}=$ blood oxygen level-dependent; $\mathrm{CMRO}_{2}=$ cerebral metabolic rate of oxygen consumption; $\mathrm{OEF}=$ oxygen-extraction fraction; $\mathrm{pO}_{2}=$ partial pressure of oxygen; $\mathrm{QBOLD}=$ quantitative $\mathrm{BOLD} ; \mathrm{QUIXOTIC}=\mathrm{QUantitative} \mathrm{Imaging} \mathrm{of} \mathrm{eXtraction} \mathrm{of} \mathrm{Oxygen} \mathrm{and} \mathrm{TIssue} \mathrm{Consumption;} \mathrm{SaO}_{2}=$ arterial oxygen saturation; $\mathrm{SO}_{2}=$ blood oxygen saturation; $\mathrm{SvO}_{2}=$ venous oxygen saturation; TRUST = T2-relaxation under spin-tagging

$\mathbf{T}$ he development of a reliable brain oxygenation mapping technique would not only enable a better understanding of normal physiology during rest, sleep, or functional brain tasks but also be of great help in managing pathophysiologic conditions in which oxygen supply is disturbed. In tumors, it has long been recognized that the lack of oxygen in tissues (hypoxia) influences the response to therapies, including aggressiveness, local recurrence, and metastasis, as well as overall prognosis. ${ }^{1,2}$ In acute stroke, a parameter that could reflect the metabolic state of the ischemic brain may improve the ability to identify tissue at risk of infarction, ${ }^{3}$ to select patients for reperfusion therapies, or to avoid thrombolytic therapy in futile situations. ${ }^{4}$ In addition, many other disorders of the brain, including Alzheimer disease, Parkinson disease, Huntington disease, and multisystem atrophy, also appear to be associated with alterations in cerebral oxygen metabolism. ${ }^{5-7}$

From the Department of Radiology (T.C., G.Z.), Stanford University, Stanford, California; Department of Radiology (D.S.B.), Athinoula A. Martinos Center for Biomedical Imaging, Massachusetts General Hospital, Charlestown, Massachusetts; and Department of Electrical Engineering and Computer Science (D.S.B.), Massachusetts Institute of Technology, Cambridge, Massachusetts.

Please address correspondence to Greg Zaharchuk, PhD, MD, Stanford University Medical Center, 1201 Welch Rd, Mail Code 5488, Stanford, CA 94305-5488; e-mail: gregz@stanford.edu

-- Indicates open access to non-subscribers at www.ajnr.org

http://dx.doi.org/10.3174/ajnr.A3070
Important criteria for a useful oxygenation imaging method include noninvasiveness, adequate spatial and temporal resolution, ability to quantify oxygenation levels, low radiation exposure, good safety profile, and widespread clinical availability. Unfortunately, no in vivo method currently fulfills all these requirements. ${ }^{8}$ The development in the late 1980 s of the polarographic needle electrode system has allowed accurate measurements of $\mathrm{pO}_{2}$ in vivo. ${ }^{9}$ Yet it provides only local measurements and is sufficiently invasive to discourage widespread use. Currently, the reference standard for tomographic whole-brain oxygenation measurement is PET, by using either oxygen-15 or hypoxia tracers, such as fluorine-18 misonidazole. However, PET is not widely available, and its use of ionizing radiation limits its repeated use in the same patient.

MR imaging is also known to be sensitive to blood oxygenation; the well-known BOLD contrast approach has been used for many years in the field of cognitive neuroscience. BOLD MR imaging is noninvasive and can be performed with high temporal and spatial resolution. However, the major drawback of the BOLD-based approach is that the relation between $\mathrm{T} 2^{*}$ and tissue oxygenation is determined by many other parameters, including macroscopic B0 inhomogeneities (shim, air/tissue interface), the transverse relaxation parameter $\mathrm{T} 2$, water diffusion, and the characteristics of the blood vessel network. Therefore, oxygenation measurements based only on $\mathrm{T} 2 *$ imaging are unlikely to be quan- 


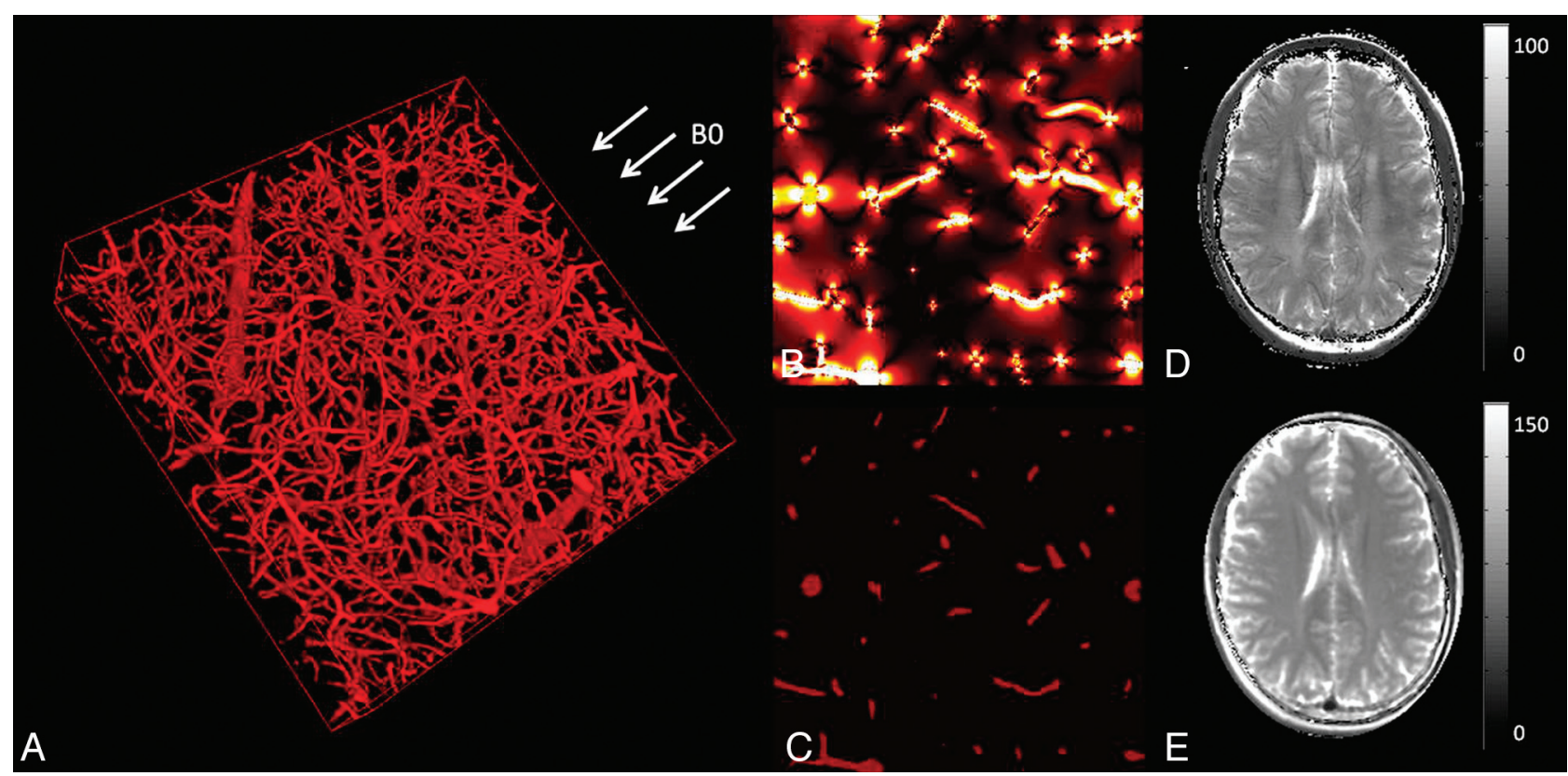

FIG 1. A, 3D representation of a microvascular network acquired with 2-photon microscopy and orientation of the MR imaging main magnetic field $B 0$. $B$, Simulation of the magnetic field distribution in 1 section of the voxel represented in $A$ when considering a blood oxygen saturation of $60 \%$. C, Blood vessel geometry in the same section as in B. High-resolution T2* map (D) and T2 map (E) acquired in a volunteer at 3T. A-C are adapted from Christen et al. ${ }^{89}$

titative and may, in fact, be misleading. ${ }^{10}$ This review article will focus on the various approaches that have been proposed during the past decade to obtain specific oxygenation measurements by using MR imaging techniques that exploit the effects of blood deoxyhemoglobin levels on proton transverse relaxivity.

\section{BOLD EFFECT}

\section{Origins and Methods}

BOLD contrast relies on a difference of magnetic susceptibility between oxyhemoglobin and deoxyhemoglobin. Oxyhemoglobin is diamagnetic, and its presence has no effect on the MR signal. When deoxygenated, the molecule has unpaired electrons and becomes paramagnetic. Because the fraction of the average brain voxel filled with blood (ie, CBV) is only approximately $4 \%$, if only intravascular MR imaging parameters were affected, the BOLD signal would be barely detectable. In fact, the magnetic field perturbations that give rise to the BOLD effect extend for a distance of up to 5 times the vessel radius, which increases its sensitivity dramatically (Fig 1). The dephasing effect is particularly strong on $\mathrm{T} 2{ }^{*}$-weighted images, which are sensitive to both spin-spin relaxation and magnetic field inhomogeneity. As a result, gradientecho sequences that use a low flip angle, long TE, and long TR are usually employed. T2-weighted images from spin-echo imaging are also affected by the BOLD effect because of the effects of the diffusion of water molecules around the vessels. ${ }^{11}$ Most interesting, the sensitivity of T2 for a given change in deoxyhemoglobin concentration varies with vessel diameter, rising rapidly and then falling off as the vessel size increases. ${ }^{11}$ On the other hand, the sensitivity of $\mathrm{T}^{*}$ measurements remains high for approximately every vessel-diameter size that is normally present in the brain. The first consequence of this observation is that $\mathrm{T} 2^{*}$ measurements (by using gradient-echo) are preferable for oxygenation measurements because they are largely independent of blood ves- sel size distribution. Second, it is possible to measure oxygenation weighted to vessels of a specific size (such as the capillaries) by adjusting the TE times to vary the diffusion effect by using spinecho sequences.

\section{Oxygenation Basics}

The $\mathrm{SO}_{2}$ is defined as the percentage of oxyhemoglobin in a vessel:

$$
\mathrm{SO}_{2}=\left[\mathrm{HbO}_{2}\right] /\left([\mathrm{dHb}]+\left[\mathrm{HbO}_{2}\right]\right),
$$

where $\left[\mathrm{HbO}_{2}\right]$ and $[\mathrm{dHb}]$ represent the concentration of oxy- and deoxyhemoglobin, respectively. With these parameters, the OEF may be defined as

$$
\mathrm{OEF}=\left(\mathrm{SaO}_{2}-\mathrm{SvO}_{2}\right) / \mathrm{SaO}_{2},
$$

where $\mathrm{SaO}_{2}$ and $\mathrm{SvO}_{2}$ represent the arterial and venous oxygen saturation, respectively. If the arterial oxygen concentration $\left(\mathrm{O}_{2}\right)_{\mathrm{a}}$ and the $\mathrm{CBF}$ are known, the $\mathrm{CMRO}_{2}$ may be determined by using the following relationship:

$$
\mathrm{CMRO}_{2}=\mathrm{OEF} \times \mathrm{CBF} \times\left[\mathrm{O}_{2}\right]_{\mathrm{a}} .
$$

A final important parameter for oxygenation measurements is the $\mathrm{pO}_{2}$, defined as the fraction of oxygen present in a gas multiplied by the total gas pressure. According to the hemoglobin dissociation curve (or Barcroft curve), $\mathrm{pO}_{2}$ and $\mathrm{SO}_{2}$ are directly linked inside the blood vessels. Therefore, BOLD measurements can be related to $\mathrm{pO}_{2}$.

These theoretic links between tissue oxygenation and BOLD can be affected by several factors. First, the magnitude of the BOLD effect depends on the total amount of deoxyhemoglobin in the voxel. Therefore, the hematocrit level and the CBV will strongly influence the conclusions about the oxygenation level. For example, with all oxygen levels being equal, a highly vascular part of a tumor will have a lower $\mathrm{T} 2{ }^{\star}$ than the corresponding 

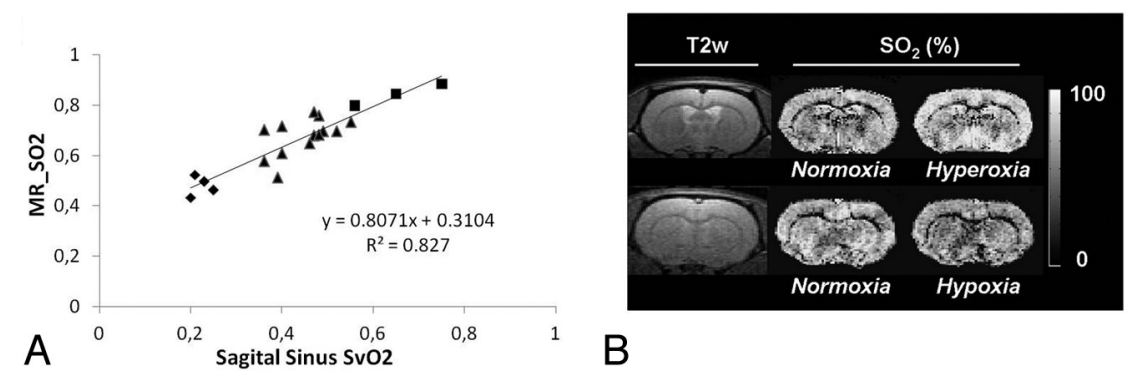

B

FIG 2. Results from a multiparametric $\mathrm{qBOLD}$ approach. $A, \mathrm{MR}$ imaging estimates of $\mathrm{SO}_{2}$ as a function of directly measured $\mathrm{SvO}_{2}$ of the sagittal sinus in rats. Squares, triangles, and diamonds represent rats under conditions of hyperoxia, normoxia, and hypoxia, respectively. $B$, Representative $\mathrm{T} 2$-weighted images and $\mathrm{SO}_{2}$ maps in control and challenge conditions in 2 rats. Adapted from Christen et al. ${ }^{21}$

contralateral tissue, due to its high CBV. Variations in temperature and $\mathrm{pH}$ changes due to variations of carbon dioxide or the addition of organic phosphate compounds will also shift or reshape the hemoglobin dissociation curve, affecting the relationship between $\mathrm{SO}_{2}$ and $\mathrm{pO}_{2}$. For BOLD to track tissue oxygenation status, it is important that red blood cells be delivered to the tissue in question. Yet studies on tumors have shown that vessels may be present but perfusion by red blood cells may not occur. ${ }^{12}$

\section{BOLD Artifacts}

BOLD images are subject to several artifacts. Signal enhancement, known as inflow effect, occurs because the signal produced by the water in blood flowing into the imaging section is much stronger than the one produced by the static spins (partially saturated by previous radio-frequency pulses). This effect can be minimized by using a multiecho gradient-echo sequence and computing the $\mathrm{T}_{2}{ }^{*}$ relaxation rate $\left(\mathrm{R} 2 *=1 / \mathrm{T} 2^{*}\right) .{ }^{13}$ Magnetic field inhomogeneities caused by magnet imperfections, poor shimming, air-tissue interfaces, metallic implants, or iron deposits can also affect the oxygenation measurements. Additionally, microscopic nuclear electron interactions between neighbor atoms give rise to a dissipative relaxation mechanism described by $\mathrm{T} 2$. This transverse relaxation time is linked to the $\mathrm{T} 2{ }^{*}$ through the parameter $\mathrm{T} 2{ }^{\prime}$, by using the relationship $1 / \mathrm{T} 2^{\star}=1 / \mathrm{T} 2+1 / \mathrm{T} 2^{\prime}$. Therefore, the presence of high water content-such as in the setting of vasogenic edema-will increase the measured $\mathrm{T} 2{ }^{*}$ independent of blood oxygenation changes.

\section{QUANTIFYING THE BOLD EFFECT}

Better understanding of the origin of the BOLD effect during the years has led the way to new types of $\mathrm{T} 2^{\star}$-based approaches. They have been integrated into mathematic models, instead of trying to reduce the previously mentioned confounding factors. Theoretically, this approach, sometimes called qBOLD, enables the extraction of only the deoxyhemoglobin effects, leading to more accurate assessment of brain oxygenation.

\section{A Mathematic Model of Spin-Dephasing}

These approaches have in common the use of a biophysical model, which was originally developed by Yablonskiy and Haacke $^{14}$ and considers the effect of spin-dephasing in the presence of a vascular network. The MR imaging voxel is modeled as 2 compartments: 1) a vascular compartment represented as an ensemble of long cylinders with negligible wall thickness with small volume fraction, and 2) an extravascular compartment surrounding those vessels. Because the theoretic equation of the field perturbation induced by a paramagnetic cylinder is known, one can derive an equation of the MR signal evolution. Perhaps somewhat unexpectedly, instead of monoexponential decay, the MR signal evolution versus time has a quadratic exponential behavior during the first few milliseconds after excitation. This feature has been exploited in some qBOLD approaches to distinguish oxygenation and CBV effects.

\section{DIFFERENT QBOLD APPROACHES}

The first validation of the qBOLD principle was by Yablonskiy ${ }^{15}$ in a phantom containing polyethylene tubes. An and $\operatorname{Lin}^{16}$ then demonstrated its applicability in human volunteers by using the method of gradient-echo sampling under the spin-echo, which, in theory, provided measurements of $\mathrm{CBV}$ and $\mathrm{SO}_{2}$. He and Yablonskiy ${ }^{17}$ refined the model by considering signal from gray matter, white matter, CSF, and blood as well as the effect of water diffusion. ${ }^{18,19}$ One interesting remark about these methods is that the $\mathrm{CBV}$ and blood oxygen saturation are observed through dephasing effects caused by the presence of deoxyhemoglobin. Therefore, if one assumes fully oxygenated arterial blood, the values that are derived represent only the venous and capillary portions of the vasculature.

Although an attractive feature of these qBOLD approaches is the determination of multiple parameters with a single noninvasive experiment, numeric simulations and phantom experiments show that reliable estimates are achieved only in the presence of a very high SNR. ${ }^{19,20}$ Particularly, the distinction between CBV and $\mathrm{SO}_{2}$ is quite challenging under normal experimental conditions. Christen et $\mathrm{al}^{21}$ recently described a multiparametric qBOLD approach that may increase the spatial resolution of the acquisitions and improve the accuracy of the oxygenation estimates by using independent measurements of B0, T2, and CBV combined with $\mathrm{T} 2{ }^{\star}$ estimates. The results show good correlation with blood gas analysis under various oxygenation conditions (Fig 2). ${ }^{21}$

\section{BOLD-BASED OXYGENATION MEASUREMENTS IN HEALTH AND DISEASE}

Both simple $\mathrm{T} 2 *$ estimates of oxygenation and qBOLD have been applied to examine changes related to different disease states. Some of the more common clinical applications are described in the following sections. 


\section{Healthy Subjects}

In vivo, An and $\operatorname{Lin}^{16}$ measured a mean cerebral oxygen saturation of $58 \pm 2 \%$ in 8 healthy subjects, in excellent agreement with prior measurements performed with oxygen-15 PET. ${ }^{22}$ However the CBV reported was approximately 3 times higher $(16 \pm 7 \%)$ than prior literature estimates. The impact of shim and intravascular signal was analyzed in further articles, ${ }^{23,24}$ and validation was performed on rats. ${ }^{25} \mathrm{He}$ and Yablonskiy ${ }^{17}$ also obtained encouraging results in 9 volunteers, measuring an OEF of $38 \pm 5 \%$ and a CBV of $1.8 \pm 0.1 \%$. In 12 healthy subjects, Christen et $\mathrm{al}^{26}$ measured CBV of $4.3 \pm 0.7 \%, \mathrm{CBF}$ of $44 \pm 6 \mathrm{~mL} / \mathrm{min} / 100 \mathrm{~g}, \mathrm{SO}_{2}$ of $60 \pm 6 \%$, and $\mathrm{CMRO}_{2}$ of $157 \pm 23 \mu \mathrm{mol} / 100 \mathrm{~g} / \mathrm{min}$, again in agreement with literature for both perfusion and oxygenation values.

\section{Cerebral Ischemia}

Simple $\mathrm{T} 2{ }^{*}$ measurements have been proposed to delineate the penumbra in acute stroke. Because it reflects the metabolic state of tissues, it could be a good alternative to the simplified concept of the mismatch between PWI and DWI. ${ }^{27}$ Small case series suggest that $\mathrm{T} 2{ }^{*}$ changes are present in patients with acute stroke. ${ }^{28-30}$ As mentioned before, lack of information about T2 and CBV makes it difficult to draw conclusions about quantitative oxygenation in such studies. This is supported by an MR imaging study of 5 patients with acute stroke with hypoxia on PET, in which no relationship between increased PET OEF and hypointensity on $\mathrm{T}^{\star}{ }^{\star}$ weighted images could be demonstrated. ${ }^{31}$

Because edema alters considerably the transverse relaxation times, other studies have measured both $\mathrm{T} 2{ }^{*}$ by using a gradient-echo sequence and $\mathrm{T} 2$ by using a spin-echo sequence, enabling measurement of T2'. Geisler et $\mathrm{al}^{32}$ analyzed data from 32 patients with acute stroke in the territory of the middle cerebral artery. T2' imaging was performed on days 1,5 , and 8 . The results showed a clear decrease of $\mathrm{T} 2{ }^{\prime}$ in the infarcted hemisphere compared with the contralateral hemisphere. Furthermore, regions outlined with $\mathrm{T} 2{ }^{\prime}$ appeared distinct from the ADC lesion, and the authors concluded that it yielded a better estimation of the penumbra. A comparison among PWI, DWI, and T2' imaging was also performed in a study involving a larger cohort of 100 patients with stroke who received intravenous thrombolytic therapy. ${ }^{33}$ Two independent readers reported that the presence of a T2' $>$ ADC mismatch was a more specific predictor of infarct growth than was the PWI-derived TTP/ADC mismatch and hence may be of clinical value in patient selection for acute stroke therapies. However, because CBV changes also occur in acute stroke, no firm conclusions about oxygenation levels can be made from these studies.

The qBOLD method has been applied to study oxygenation in a rat stroke model. ${ }^{25}$ These authors found that $\mathrm{SO}_{2}$ was significantly lower within the areas of eventual infarction than within other regions and that the values within the ischemic territory decreased with time. Several reports of the use of qBOLD in human cerebrovascular disease have been reported. Lee et $\mathrm{al}^{34} \mathrm{dem}$ onstrated that the $\mathrm{CMRO}_{2}$ measured by MR imaging by using the qBOLD approach in acute ischemic stroke was reduced most severely in tissue that eventually infarcted, with smaller reductions in regions of the perfusion deficit that were spared on follow-up imaging. Xie et $\mathrm{al}^{35}$ showed that hypoxic brain regions can be visualized in patients with steno-occlusive disease of the carotid artery by using the qBOLD technique. Finally, sequences that can acquire multiple gradient-echo and spin-echo images simultaneously $^{36}$ may enable rapid assessment of $\mathrm{T} 2^{\prime}$ and $\mathrm{CBV}$, which is important during the initial diagnostic evaluation of acute stroke (Fig 3$)^{37}$

\section{Tumor Hypoxia}

Punwani et $\mathrm{al}^{38}$ found a strong linear relationship between R2* and $\mathrm{dHb}$ (estimated by using near-infrared spectroscopy) in neonatal piglets exposed to different fractional inspired oxygen concentrations. However, there is evidence that $\mathrm{R} 2{ }^{\star}$ does not measure or correlate directly with $\mathrm{pO}_{2}$ values in tumors. Baudelet and Gallez ${ }^{39}$ reported a poor correlation between $\mathrm{R} 2^{\star}$ and measurements of $\mathrm{pO}_{2}$ by using fiber optic electrodes in murine tumors during respiratory challenges, while Chopra et $\mathrm{al}^{40}$ also showed a weak relationship in human prostate cancer. Contrary to this, a significant link was found between R2* and pimonidazole histology (a marker of cellular hypoxia) in patients with prostate carcinoma undergoing radical prostatectomy. ${ }^{41}$ The results showed that the sensitivity of R2* in depicting tumor hypoxia was high (88\%), but its sensitivity was low (36\%). McPhail and Robinson ${ }^{42}$ found good correlation between pimonidazole adduct formation and tumor $\mathrm{R} 2^{*}\left(1 / \mathrm{T} 2^{*}\right)$ in a rat mammary tumor model, but paradoxically, the less hypoxic tumors had higher R2*. The conflicting results of these animal studies may indicate that independent $\mathrm{CBV}$ measurements are required to interpret changes in $\mathrm{T}^{*}$, as mentioned above.

The potential prognostic ability of $\mathrm{T} 2{ }^{*}$ in tumor was reported by Rodrigues et al. ${ }^{43}$ They showed that 2 animal tumor models that exhibit different baseline value of $\mathrm{R} 2^{*}$ also showed radiotherapeuic outcomes. The rat $\mathrm{GH} 3$ prolactinoma, which exhibits a relatively high $\mathrm{R} 2 *$ before radiation therapy, showed a substantial reduction in normalized tumor volume 7 days after 15-Gy irradiation, while murine radiation-induced fibrosarcoma-1 fibrosarcomas with low $\mathrm{R} 2 *$ before treatment grew more rapidly. At this time, there are no $\mathrm{qBOLD}$ or $\mathrm{T}^{\star}$ studies evaluating tumor oxygenation in humans, to our knowledge.

\section{CHALLENGE PARADIGMS}

Dynamic approaches have been proposed to avoid some of the problems inherent to oxygenation imaging with BOLD. By observing the spatial and temporal variations of the MR signal in response to an external stimulus, static artifacts such as field inhomogeneity and T2 variation are minimized. The best-known and most widely used stimulus, task-based activation, is the basis of fMRI. However, other challenges can be applied, most of which affect either $\mathrm{O}_{2}$ directly (such as $100 \%$ oxygen gas inhalation) or indirectly through the strong $\mathrm{CO}_{2}$ effects on brain hemodynamics (such as carbogen $\left[95 \% \mathrm{O}_{2}, 5 \% \mathrm{CO}_{2}\right]$ gas inhalation, breathhold, and acetazolamide). For example, in the normal brain, changes in the fraction of inspired oxygen from air $\left(21 \% \mathrm{O}_{2}\right)$ to $100 \%$ oxygen produce changes in MR signal ranging from $>30 \%$ in large veins to $1.71 \pm 0.14 \%$ in the basal ganglia and $0.82 \pm 0.08 \%$ in white matter. ${ }^{44}$ Caffeine, hyperthermia, or drugs such as hydralazine or 

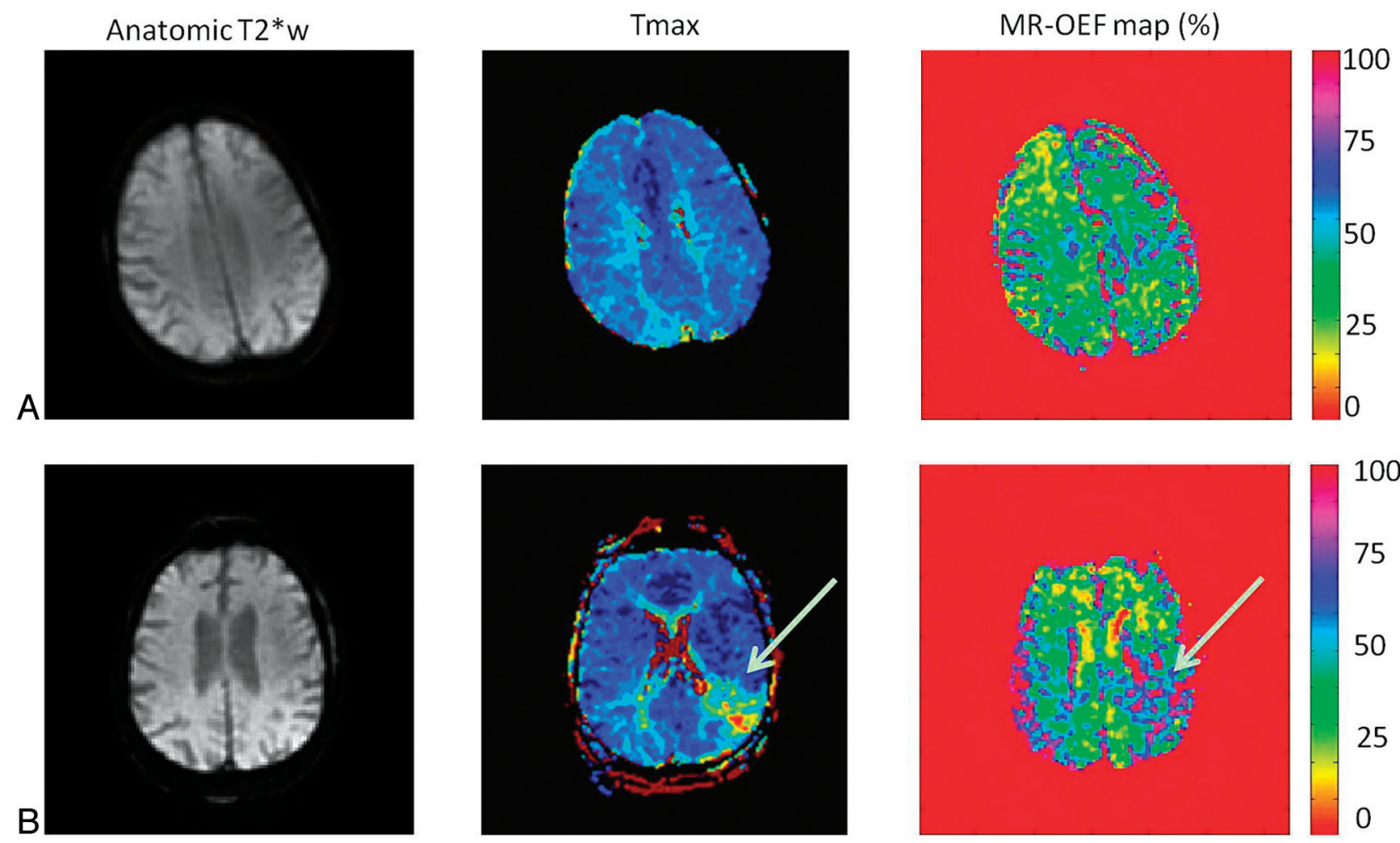

FIG 3. Parametric maps obtained with a quantitative BOLD approach by using a multiecho gradient-echo and spin-echo echo-planar imaging method in a healthy subject $(A)$ and a patient with stroke $(B)$. High OEF can be observed in the affected region of the patient with stroke (white arrow). This method holds promise to evaluate the brain oxygenation status in a rapid fashion, which is critical in the acute stroke work-up. Adapted from Christen et al. ${ }^{37}$

nicotinamide have also been proposed as global oxygenation modifiers. ${ }^{13,45}$

The main application of the observations of dynamic BOLD changes in response to extrinsic challenges has been the development of the quantitative fMRI method. ${ }^{46}$ The results from hypercapnic experiments in volunteers can be used to calibrate the BOLD signal and obtain quantitative variations of the $\mathrm{CMRO}_{2}$ during functional activation. Oxygen used as a contrast agent may also provide a noncontrast method of obtaining quantitative CBV maps ${ }^{47}$ or the vessel-size index. ${ }^{48}$

\section{Cerebral Ischemia}

Oxygen challenges have been recently evaluated in the context of stroke. In a model of permanent middle cerebral artery occlusion in rats, ${ }^{49} 5$ minutes of breathing $100 \% \mathrm{O}_{2}$ induced different signal changes within the contralateral cortex, ipsilateral cortex within the PWI/DWI mismatch zone, and ischemic core. Furthermore, the correlation with histology revealed a significant difference between the $\mathrm{T} 2{ }^{*}$ signal increase in the histologically defined borderzone compared with the ischemic core. The first clinical application of $\mathrm{T} 2^{\star}$-weighted MR imaging during oxygen challenge was presented by Dani et al. ${ }^{50}$ In 18 patients with stroke, the area under the curve, gradient of the signal increase, time to maximum signal, and percentage signal change after breathing $100 \% \mathrm{O}_{2}$ were measured. Results showed that these parameters within the diffusion lesion were smaller compared with normal tissue. Curves in the presumed penumbral regions showed varied morphology, but at hyperacute time points ( $<8$ hours), they exhibited a tendency to greater percentage signal change. Studies in patients with Moyamoya disease and steno-occlusive disease have been performed by using carefully controlled mixtures of $\mathrm{O}_{2}$ and $\mathrm{CO}_{2}$. These have shown that there is good correspondence between regions with abnormal $\mathrm{R} 2{ }^{*}$ changes and poor cerebrovascular reactivity, ${ }^{51,52}$ which may have prognostic implications. ${ }^{53}$

\section{Tumor Hypoxia}

Numerous applications of dynamic BOLD following external stimulus have been performed in tumors. Carbogen has been extensively used because of its large effect on the MR signal (Fig 4). Taylor et $\mathrm{al}^{54}$ investigated a wide range of tumors (lymphoma, squamous carcinoma, transitional carcinoma, adenocarcinoma, and so forth), demonstrating significant increases in BOLD signal (range, $6.5 \%-82 \%$ ) with carbogen breathing in $60 \%$ of cases. Furthermore, Rodrigues et $\mathrm{al}^{43}$ showed that carbogen-induced $\Delta \mathrm{R} 2^{*}$ is an informative parameter with respect to potential radiotherapeutic outcome. A greater magnitude of the response to carbogen was associated with a better radiotherapeutic response. Additional investigations have shown good correlations between R2* changes and tumor $\mathrm{pO} 2$ in animals by using reference standards of either polarographic electrodes, ${ }^{55}$ electron paramagnetic resonance, ${ }^{56}$ fluorine-19 perfluorocarbon MR imaging measurements, ${ }^{57}$ or pimonidazole adduct formation. ${ }^{42}$ These encouraging results were, however, challenged by the work by Baudelet and Gallez. ${ }^{39}$ In their study, the evolution of the local BOLD response in a rat tumor model was temporally correlated with local $\mathrm{pO}_{2}$ change, but there was no correlation of the BOLD signal amplitude with absolute $\mathrm{pO}_{2}$. Moreover, the sensitivity of $\mathrm{R}^{\star}$ to the change in $\mathrm{pO}_{2}$ varied among tumor types.

AJNR Am J Neuroradiol 34:1113-23 Jun 2013 www.ajnr.org 1117 

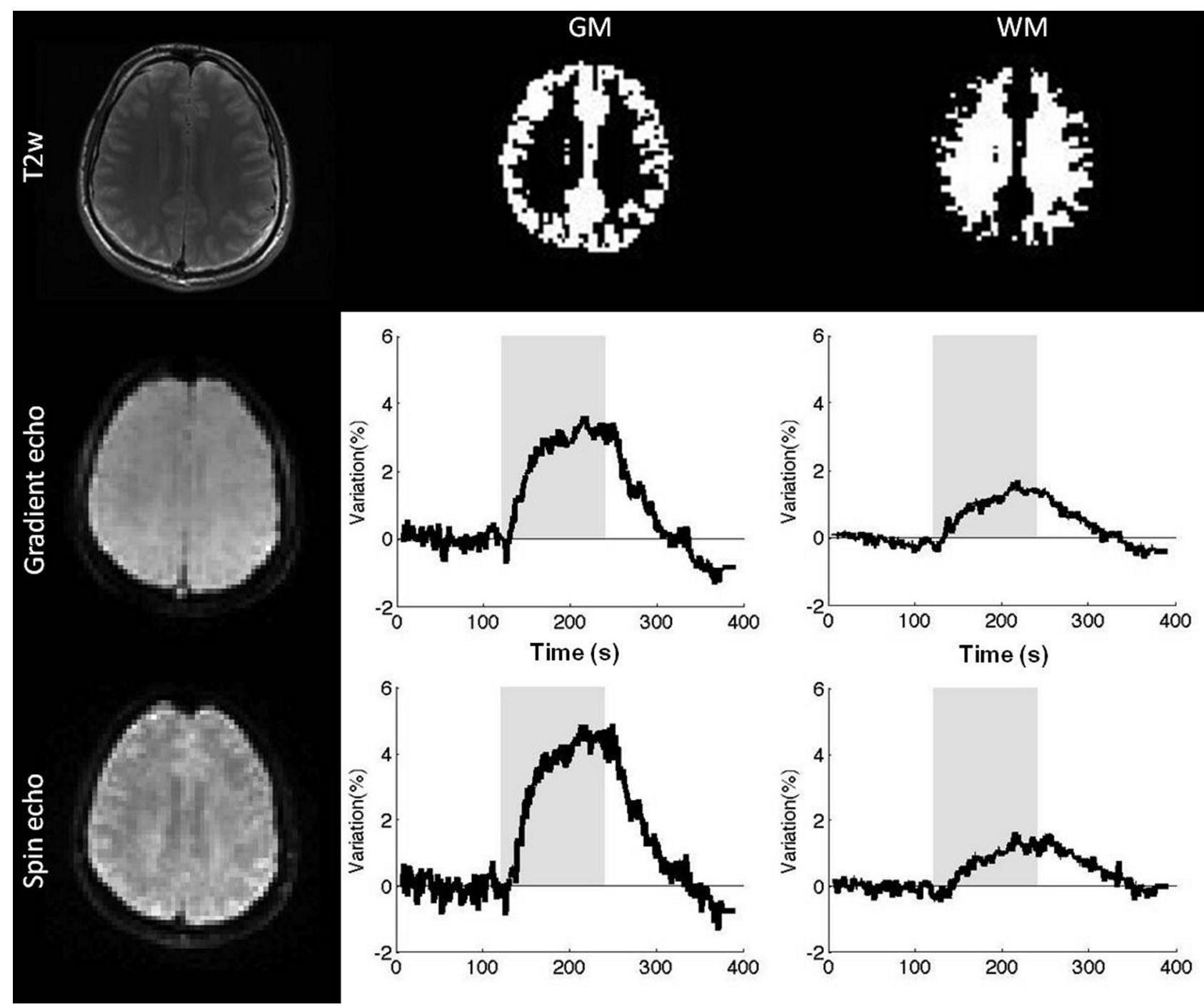

FIG 4. Oxygen-sensitive MR imaging in the setting of cerebrovascular challenge during a 2-minute inhalation of carbogen gas $\left(95 \% \mathrm{O}_{2}, 5 \% \mathrm{CO}_{2}\right)$. Images were acquired by using a multiple spin- and gradient-echo pulse sequence that enables the measurement of $\mathrm{T}^{*}$ and $\mathrm{T} 2{ }^{*}$ with high temporal resolution. Note the increase in signal corresponding to decreased $\mathrm{T} 2$ and $\mathrm{T} 2^{*}$ during carbogen inhalation (gray column).

The major limitation of BOLD challenge approaches is the fact that they do not measure absolute tissue $\mathrm{SO}_{2}$ directly and have low SNR. In addition, carbogen inhalation is somewhat poorly tolerated in humans (approximately $25 \%-35 \%$ of patient examinations fail due to respiratory distress). ${ }^{58}$ These approaches could, however, be useful to guide the design of new and more effective tumor oxygenating agents (which have shown only marginal effect on the radiosensitivity of human tumors ${ }^{55}$ ) and to optimize treatments for individual patients. This technique could also offer a possible novel approach to metabolic imaging in acute stroke and provide a more precise assessment of penumbra. Finally, in addition to examining $\mathrm{T} 2{ }^{\star}$, the shortening of the tissue water $\mathrm{T} 1$ value during hyperoxic gas breathing has been proposed to measure oxygenation. ${ }^{59,60}$ A combination of $\Delta \mathrm{R} 2^{\star}$ and $\Delta \mathrm{R} 1$ measurements may yield new insights into brain tissue oxygenation.

\section{USING MR PHASE TO MEASURE OXYGENATION}

Although not usually exploited, the phase information of the MR signal can be an excellent source of contrast. ${ }^{61}$ The phase shift in a gradient-echo image represents the average magnetic field in a voxel, which depends on the local magnetic susceptibility. As a consequence, relative abundance of the paramagnetic substances such as myelin or iron can be imaged with phase imaging. In the context of oxygenation, methods that take advantage of the difference in magnetic susceptibility between deoxygenated blood and the surrounding tissue have also been proposed.

\section{Susceptibility-Based Oximetry}

Blood oxygen saturation of major vessels (eg, the superior sagittal sinus) can be obtained by measuring the phase difference $(\Delta \phi)$ between blood and surrounding brain parenchyma in a flowcompensated image, ${ }^{62}$ by using the following relationship:

$$
\Delta \phi=\gamma \times \Delta \mathrm{B} \times \mathrm{TE},
$$

where $\Delta \mathrm{B}$ represents the difference in the magnetic field between the 2 compartments and TE. By modeling the blood vessel as a long paramagnetic cylinder, an exact expression for the incremental field $\Delta \mathrm{B}$ can be derived as

$$
\Delta \mathrm{B}=1 / 6 \times \Delta \chi_{\text {do }} \times \operatorname{Hct} \times(1-\mathrm{SO} 2) \times \mathrm{B} 0 \times\left(3 \cos ^{2} \theta-1\right),
$$




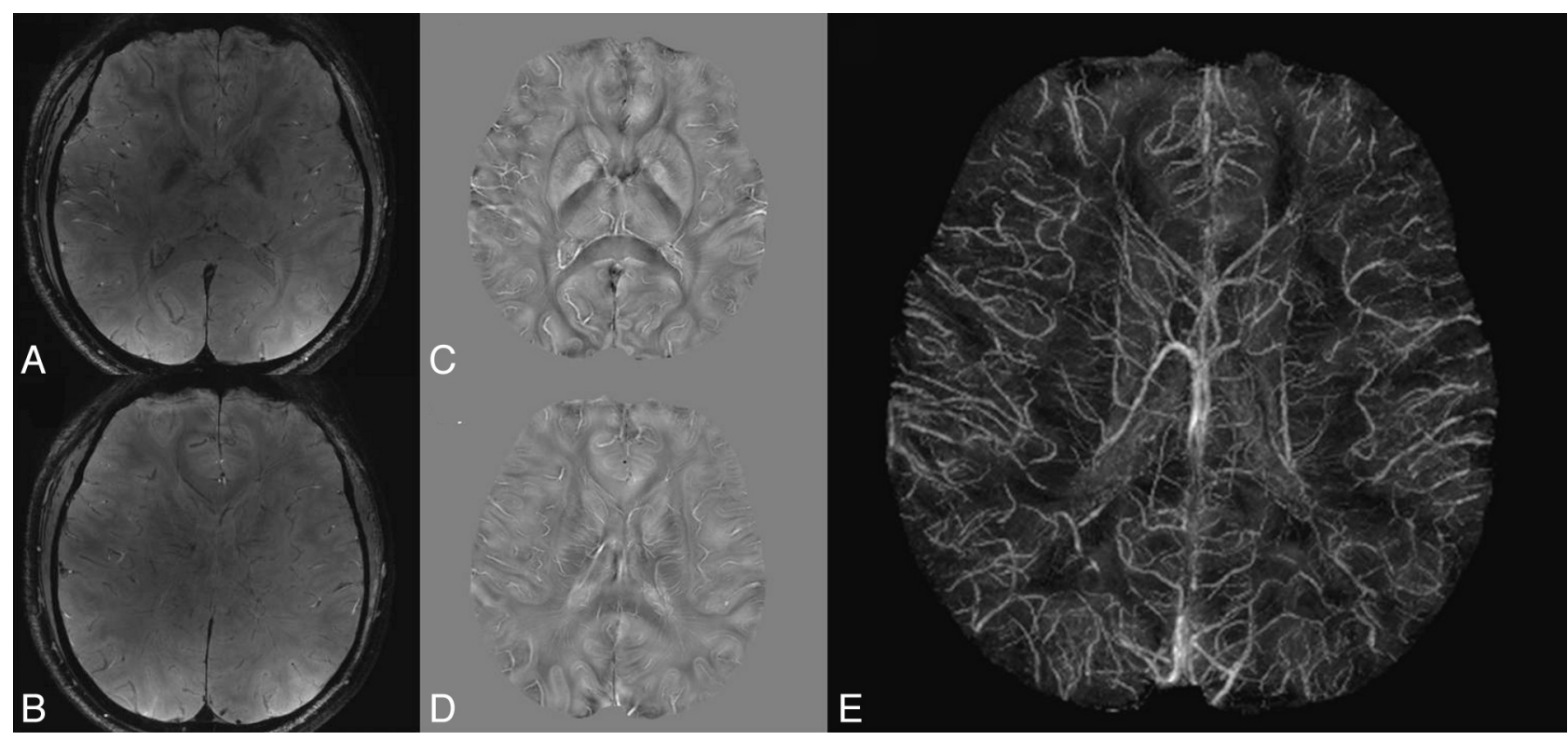

FIG 5. Quantitative magnetic susceptibility mapping in a volunteer at 7T. $A$ and $B$, Gradient-echo weighted images. $C$ and $D$, Corresponding magnetic susceptibility maps. E, Maximum intensity projection of the magnetic susceptibility maps over a 20-mm slab. Courtesy of Drs D. Qiu and M. Moseley, Stanford University.

where $\Delta \chi_{\text {do }}=0.27 \mathrm{ppm}$ (in centimeter-gram-second units) and is the susceptibility difference between fully deoxygenated and fully oxygenated erythrocytes and $\theta$ is the angle of the cylinder relative to the applied field $\mathrm{B} 0$. If the hematocrit (Hct) is known (eg, determined from a blood sample), the only unknown is the oxygen saturation $\left(\mathrm{SO}_{2}\right)$.

Fernandez-Seara et $\mathrm{al}^{63}$ measured an $\mathrm{SvO}_{2}$ of $66 \pm 8 \%$ in the internal jugular vein of 5 volunteers and a decrease in oxygen saturation of $7 \pm 3 \%$ during breathhold. Another study assessed oxygenation in pial veins of 5 volunteers, ${ }^{64}$ measuring $\mathrm{SO}_{2}=$ $54 \pm 3 \%$. If the blood flow is also quantified in the major inflow vessels (internal carotid arteries and vertebral arteries) by using phase-contrast MR imaging, ${ }^{65}$ an estimate of the global $\mathrm{CMRO}_{2}$ may be obtained. Using this principle, Jain et $\mathrm{al}^{66}$ reported a global brain $\mathrm{SO}_{2}$ of $64 \pm 4 \%, \mathrm{CBF}$ of $45 \pm 3 \mathrm{~mL} / 100 \mathrm{~g} / \mathrm{min}$, and $\mathrm{CMRO}_{2}$ of $127 \pm 7 \mathrm{~mol} / 100 \mathrm{~g} / \mathrm{min}$.

This technique is noninvasive, includes self-calibration, has equal sensitivity to all oxygenation levels, and is relatively straightforward to implement. Possible errors resulting from vessel tilt, noncircularity of vessel cross-section, and induced magnetic field gradients have been evaluated. ${ }^{67,68}$ These effects are generally low, and methods for correction have already been designed and implemented. The main drawback of susceptometry-based oximetry remains that only medium- to large-sized vessels can be targeted, providing mainly global brain oxygen information, though a recent study has proposed extending the technique to smaller veins with favorable orientations. ${ }^{69}$

\section{Susceptibility Mapping}

Recently, a new technique called susceptibility imaging has been proposed to derive quantitative susceptibility maps from MR phase images. Susceptibility imaging uses recent mathematic developments initially designed for rapidly simulating the field shifts produced by arbitrary susceptibility distributions. ${ }^{70,71}$ With a dipolar field approximation, there is a simple expression that links phase and susceptibility $(\chi)$ :

$$
\mathrm{FT}(\phi)=\gamma \times \mathrm{B} 0 \times \mathrm{TE} \times \mathrm{FT}(\chi) \times\left(1 / 3-\mathrm{k}_{\mathrm{z}}^{2} / \mathrm{k}^{2}\right),
$$

where FT denotes a Fourier transform, $\mathrm{k}_{\mathrm{z}}$ is the $\mathrm{z}$-component of the $k$-space vector parallel to the main magnetic field, and $\mathrm{k}$ is the magnitude of the $k$-space vector. Quantitative maps of susceptibility may be obtained by inverting this equation. However, this process is ill-posed because it cannot be accurately determined in regions near the conical surfaces defined by $\mathrm{k}^{2}-3 \mathrm{k}_{\mathrm{z}}^{2}=0$. A variety of approaches have been proposed to address this issue, including thresholding to avoid division by zero, ${ }^{72,73}$ multiple acquisitions while the object is rotated in the scanner, ${ }^{74,75}$ and Bayesian regularization of the inverse problem. ${ }^{76,77}$

Susceptibility mapping has many possible applications, including accurate in vivo measurement of the concentration of contrast agents as well as investigation of the relationship between iron content and the progression of neurodegenerative diseases. To date, only 1 study ${ }^{78}$ has focused on blood oxygenation measurements by using susceptibility mapping, and it found that the major veins in the brain could be visualized. Technical developments are still needed to improve spatial resolution, reduce artifacts, increase the temporal resolution, and evaluate the range of blood oxygen sensitivity that is achievable. However, susceptibility imaging is likely to be a formidable tool to investigate blood oxygenation, even in small vessels (Fig 5).

\section{USING INTRAVASCULAR T2 TO MEASURE OXYGENATION}

In contrast to $\mathrm{T}^{*}$ and $\mathrm{qBOLD}$ methods, which target the effects of $\mathrm{dHb}$ on extravascular tissue signal, an alternative approach involves quantifying $\mathrm{dHb}$-induced signal loss in intravascular blood. These techniques invoke an MR signal model that estab- 

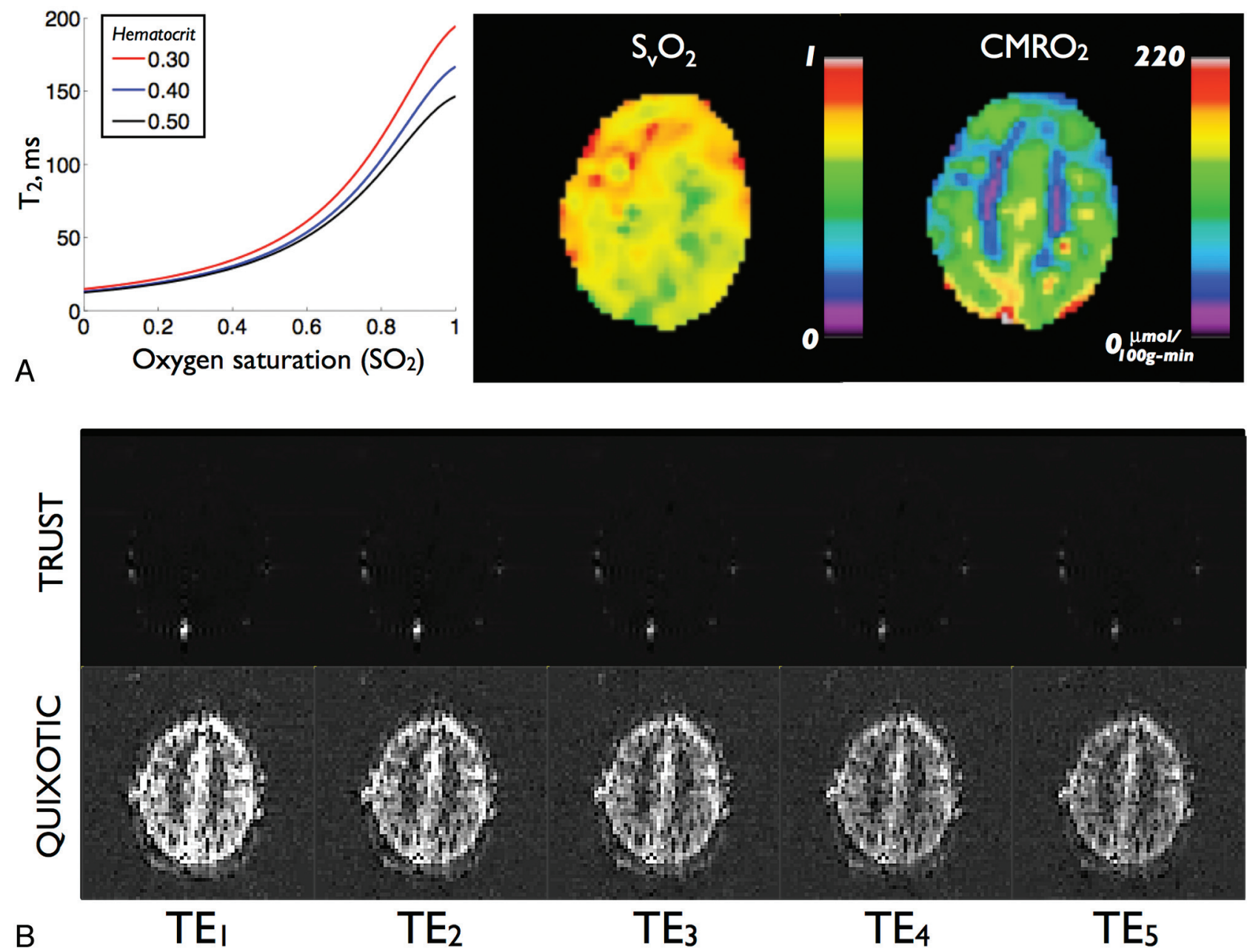

FIG 6. Results from intravascular T2-based approaches. $A$, Sample $\mathrm{T} 2$ versus $\mathrm{SO}_{2}$ calibration curve for several hematocrit levels. B, Representative venous-blood-weighted images at multiple TEs for TRUST (top row) and QUIXOTIC (bottom row). Adapted from Bolar et al. ${ }^{87}$

lishes an analytic relationship between the blood $\mathrm{T} 2$ relaxation, $\mathrm{SO}_{2}$, and hematocrit and excludes signal contributions from extravascular constituents. The model has been extensively described ${ }^{79-82}$ and recently applied in humans at $3 \mathrm{~T} .{ }^{83}$ With this model, T2-versus- $\mathrm{SO}_{2}$ calibration curves can be generated and used to convert venous blood T2 to absolute $\mathrm{SvO}_{2}$ (Fig 6A).

The major challenge in using intravascular $\mathrm{T} 2$ to measure $\mathrm{SvO}_{2}$ is isolating pure venous blood signal that is free from extravascular and nonvenous blood components. If this obstacle can be overcome, intravascular methods offer several advantages. First, they are relatively insensitive to non-dHb sources of magnetic field variation, such as static field heterogeneity and tissue iron differences. Second, because signal originates solely from intravascular blood, the percentage contribution of extravascular voxel constituents does not need to be assumed or measured. Third, because empiric $\mathrm{T} 2$ and $\mathrm{SO}_{2}$ relationships can be established in vitro with pure blood phantoms, calibration curves for a specific experimental setup and field strength can be determined empirically. As such, exact values of difficult-to-measure biophysical model parameters are not required.

Isolating pure venous blood signal, however, is a nontrivial task. This is primarily due to partial voxel voluming with tissue, CSF, and nonvenous blood. To circumvent this issue, initial in- travascular T2 studies targeted blood in large veins only. ${ }^{80,82}$ These studies used BOLD contrast to first locate draining veins from active sites and then measured $\mathrm{T} 2$ and $\mathrm{SvO}_{2}$ in voxels within these vessels. Despite careful voxel selection, however, limits on spatial resolution make partial volume effects difficult to avoid.

\section{TRUST}

More recently, spin-labeling-based approaches have been creatively used to isolate venous blood signal. $\mathrm{Lu}$ and $\mathrm{Ge}$ proposed TRUST MR imaging and measured $\mathrm{SvO}_{2}$ in the sagittal sinus. ${ }^{84}$ TRUST uses pulsed arterial spin-labeling MR imaging theory, ${ }^{85}$ but instead labels blood on the venous side of circulation. Paired subtraction (as in typical arterial spin-labeling data processing) results in an image containing blood signal from large veins only, with tissue and CSF completely removed. If one acquires these images at multiple echo times and measuring T2 in a large vein, it is possible to measure global $\mathrm{SvO}_{2}$. Figure $6 \mathrm{~B}$ (top row) shows representative multiecho TRUST images; T2 signal decay within the sagittal sinus is demonstrated. TRUST has been recently applied and validated in humans, with a study of 17 subjects reporting mean global $\mathrm{SvO}_{2}$ of $63 \pm 5 \%$, CBF of $43 \pm 7 \mathrm{~mL} / \mathrm{min} / 100 \mathrm{~g}$, and $\mathrm{CMRO}_{2}$ of $132 \pm 20 \mu \mathrm{mol} / \mathrm{min} / 100$ g. ${ }^{86}$ Despite being a spin-labeling technique, TRUST has high SNR due to the large 
blood volume within draining vein voxels and can thus be accurately performed in minutes. A limitation of TRUST is that measurements are restricted to terminal veins, making regional $\mathrm{SvO}_{2}$ estimation difficult.

\section{QUIXOTIC}

A second approach dubbed QUIXOTIC extends the utility of spin-labeling and isolates venous blood on a voxel-by-voxel basis, thus allowing localized $\mathrm{SvO}_{2}$ measurements. ${ }^{87}$ QUIXOTIC uses a velocity-selective excitation scheme that is related to velocity-selective arterial spin-labeling. ${ }^{88}$ In principle, QUIXOTIC applies velocity-sensitive pulses to eliminate signal from blood flowing above preset cutoff velocities. By carefully timing these pulses, one can exploit the physiologic blood velocity distribution and create a venular-blood bolus that persists after arterial spin-labeling subtraction. ${ }^{87}$ Signal from static tissue, CSF, and nonvenular blood compartments is eliminated, resulting in a pure venular-blood map. As in TRUST, QUIXOTIC venous blood-weighted images are acquired at multiple TEs (Fig 6B) to generate T2 maps from which $\mathrm{SvO}_{2}, \mathrm{OEF}$, and $\mathrm{CMRO}_{2}$ images are subsequently computed (Fig 6C). QUIXOTIC performed in 10 healthy subjects found a mean gray matter $\mathrm{SvO}_{2}$ of $73 \pm 2 \%$, CBF of $56 \pm 8$ $\mathrm{mL} / \mathrm{min} / 100 \mathrm{~g}$, OEF of $26 \pm 2 \%$, and $\mathrm{CMRO}_{2}$ of $125 \pm 15 \mu \mathrm{mol} /$ $\mathrm{min} / 100 \mathrm{~g}$. Notably, QUIXOTIC reports parenchymal $\mathrm{SvO}_{2}$ values higher than those reported by qBOLD and PET methods. The source of this discrepancy is currently under investigation; an in-depth discussion can be found in Bolar et al. ${ }^{87}$ The main limitation of QUIXOTIC is low SNR, due to low CBV in a typical parenchymal voxel. This is expected to become less of an issue at higher field strengths and with the use of multiple-element imaging coils. Notably, like arterial spin-labeling, QUIXOTIC can be used in functional imaging to create quantitative $\mathrm{SvO}_{2}$ and $\mathrm{OEF}$ activation maps.

\section{CONCLUSIONS}

These different MR imaging approaches to assess brain oxygenation have great potential, because they are noninvasiveness, have high temporal and spatial resolution, and may be repeated under different conditions, including cerebrovascular reactivity challenges. While each approach has its own advantages and disadvantages, combinations of these methods may complement each other to correct for possible artifacts and incorporate new physiologic information to obtain a global vision of blood oxygenation. For example, phase data about mid-to-large-sized vessels can be analyzed in parallel with the data from qBOLD results on the microvasculature. These results would also help to correct the $\mathrm{T} 2{ }^{*}$ acquisitions due to macroscopic inhomogeneities or the presence of other sources of magnetic susceptibility such as of tissue iron. A combination of $\mathrm{R} 2^{\star}$ and $\Delta \mathrm{R} 2^{*}$ (from cerebrovascular challenge studies) could lead to a distinction between tissues that are hypoxic but still can or cannot respond to an oxygenation challenge. The future research directions for MR oximetry may extend beyond the quest for absolute values of oxygenation such as $\mathrm{SO}_{2}$ or $\mathrm{pO}_{2}$ per se. Instead, the significance of these methods may be their relationship to treatment response and the opportunity to guide the development of oxygenating agents, which would have significant clinical impact.
Disclosures: Divya Bolar_UNRELATED: Patents (planned, pending, or issued): I have a patent pending called "System and Method to Analyze Blood Parameters using Magnetic Resonance Imaging," of which I am an inventor. No money has been paid to me or my institution. Greg Zaharchuk-UNRELATED: Consultancy: GE Healthcare Neuroradiology Advisory Board, Grants/Grants Pending: numerous National Institutes of Health grants; some research support from GE Healthcare.

\section{REFERENCES}

1. Gray LH, Conger AD, Ebert M, et al. The concentration of oxygen dissolved in tissues at the time of irradiation as actor in radiotherapy. Br J Radiol 1953;26:638-48

2. Brown JM, Wilson WR. Exploiting tumour hypoxia in cancer treatment. Nat Rev Cancer 2004;4:437-47

3. Kidwell CS, Alger JR, Saver JL. Beyond mismatch: evolving paradigms in imaging the ischemic penumbra with multimodal magnetic resonance imaging. Stroke 2003;34:2729-35

4. Röther J, Schellinger PD, Gass A, et al. Effect of intravenous thrombolysis on MRI parameters and functional outcome in acute stroke $<6$ hours. Stroke 2002;33:2438-45

5. Ishii K, Kitagaki H, Kono M, et al. Decreased medial temporal oxygen metabolism in Alzheimer's disease shown by PET. J Nucl Med 1996;37:1159-65

6. Karimi M, Golchin N, Tabbal SD, et al. Subthalamic nucleus stimulation-induced regional blood flow responses correlate with improvement of motor signs in Parkinson disease. Brain 2008;131(pt 10):2710-19

7. Beal MF. Mitochondria, oxidative damage, and inflammation in Parkinson's disease. Ann N Y Acad Sci 2003;991:120-31

8. Vikram DS, Zweier JL, Kuppusamy P. Methods for noninvasive imaging of tissue hypoxia. Antioxid Redox Signal 2007;9:1745-56

9. Vaupel P, Schlenger K, Knoop C, et al. Oxygenation of human tumors: evaluation of tissue oxygen distribution in breast cancers by computerized $\mathrm{O}_{2}$ tension measurements. Cancer Res 1991;51:3316-22

10. Christen T, Lemasson B, Pannetier N, et al. Is T2* Enough to assess oxygenation? Quantitative blood oxygen level-dependent analysis in brain tumor. Radiology 2011;262:495-502

11. Boxerman JL, Hamberg LM, Rosen BR, et al. MR contrast due to intravascular magnetic susceptibility perturbations. Magn Reson Med 1995;34:555-66

12. Robinson SP, Rijken PF, Howe FA, et al. Tumor vascular architecture and function evaluated by non-invasive susceptibility MRI methods and immunohistochemistry. J Magn Reson Imaging 2003; 17:445-54

13. Baudelet C, Gallez B. Current issues in the utility of blood oxygen level dependent MRI for the assessment of modulations in tumor oxygenation. Current Medical Imaging Reviews 2005;1:229-43

14. Yablonskiy DA, Haacke EM. Theory of NMR signal behavior in magnetically inhomogeneous tissues: the static dephasing regime. Magn Reson Med 1994;32:749-63

15. Yablonskiy DA. Quantitation of intrinsic magnetic susceptibilityrelated effects in a tissue matrix: phantom study. Magn Reson Med 1998;39:417-28

16. An H, Lin W. Quantitative measurements of cerebral blood oxygen saturation using magnetic resonance imaging. J Cereb Blood Flow Metab 2000;20:1225-36

17. He X, Yablonskiy DA. Quantitative BOLD: mapping of human cerebral deoxygenated blood volume and oxygen extraction fraction: default state. Magn Reson Med 2007;57:115-26

18. Dickson JD, Ash TW, Williams GB, et al. Quantitative BOLD: the effect of diffusion. J Magn Reson Imaging 2010;32:953-61

19. Sohlin MC, Schad LR. Susceptibility-related MR signal dephasing under nonstatic conditions: experimental verification and consequences for qBOLD measurements. J Magn Reson Imaging 2011;33:417-25

20. Sedlacik J, Reichenbach JR. Validation of quantitative estimation of tissue oxygen extraction fraction and deoxygenated blood volume 
fraction in phantom and in vivo experiments by using MRI. Magn Reson Med 2010;63:910-21

21. Christen T, Lemasson B, Pannetier N, et al. Evaluation of a quantitative blood oxygenation level-dependent (qBOLD) approach to map local blood oxygen saturation. NMR Biomed 2010 Oct 19. [Epub ahead of print]

22. Leenders KL, Perani D, Lammertsma AA, et al. Cerebral blood flow, blood volume and oxygen utilization: normal values and effect of age. Brain 2011;24:393-403

23. An H, Lin W. Cerebral oxygen extraction fraction and cerebral venous blood volume measurements using MRI: effects of magnetic field variation. Magn Reson Med 2002;47:958-66

24. An H, Lin W. Cerebral venous and arterial blood volumes can be estimated separately in humans using magnetic resonance imaging. Magn Reson Med 2002;48:583-88

25. An H, Liu Q, Chen Y, et al. Evaluation of MR-derived cerebral oxygen metabolic index in experimental hyperoxic hypercapnia, hypoxia, and ischemia. Stroke 2009;40:2165-72

26. Christen T, Schmiedeskamp H, Straka M, et al. Measuring brain oxygenation in humans using a multiparametric quantitative blood oxygenation level dependent MRI approach. Magn Reson Med 2012; 68:905-11

27. Sobesky J, Zaro Weber O, Lehnhardt FG, et al. Does the mismatch match the penumbra? Magnetic resonance imaging and positron emission tomography in early ischemic stroke. Stroke 2005;36:980-85

28. Tamura H, Hatazawa J, Toyoshima $\mathrm{H}$, et al. Detection of deoxygenation-related signal change in acute ischemic stroke patients by T2*-weighted magnetic resonance imaging. Stroke 2002;33:967-71

29. Wardlaw JM, von Heijne A. Increased oxygen extraction demonstrated on gradient echo $\left(\mathrm{T}^{*}\right)$ imaging in a patient with acute ischaemic stroke. Cerebrovasc Dis 2006;22:456-58

30. Morita $N$, Harada $M$, Uno $M$, et al. Ischemic findings of $T 2^{*}-$ weighted 3-Tesla MRI in acute stroke patients. Cerebrovasc Dis 2008;26:367-75

31. Donswijk ML, Jones PS, Guadagno JV, et al. T2*-weighted MRI versus oxygen extraction fraction PET in acute stroke. Cerebrovasc Dis 2009;28:306-13

32. Geisler BS, Brandhoff F, Fiehler J, et al. Blood-oxygen-level-dependent MRI allows metabolic description of tissue at risk in acute stroke patients. Stroke 2006;37:1778-84

33. Siemonsen $S$, Fitting $T$, Thomalla G, et al. T2' imaging predicts infarct growth beyond the acute diffusion-weighted imaging lesion in acute stroke. Radiology 2008;248:979-86

34. Lee J-M, Vo KD, An H, et al. Magnetic resonance cerebral metabolic rate of oxygen utilization in hyperacute stroke patients. Ann Neurol 2003;53:227-32

35. Xie S, Hui LH, Xiao JX, et al. Detecting misery perfusion in unilateral steno-occlusive disease of the internal carotid artery or middle cerebral artery by $\mathrm{MR}$ imaging. AJNR Am J Neuroradiol 2011;32:1504-09

36. Schmiedeskamp H, Straka M, Newbould RD, et al. Combined spinand gradient-echo perfusion-weighted imaging. Magn Reson Med. 2012;68:30-40

37. Christen T, Schmiedeskamp H, Straka M, et al. Rapid measurement of oxygen extraction fraction (OEF) maps using a combined multiple gradient and spin echo bolus contrast sequence. In: Proceedings of the 19th Annual Meeting of International Society for Magnetic Resonance in Medicine, Montreal, Quebec, Canada. May 6-13, 2011

38. Punwani S, Ordidge RJ, Cooper CE, et al. MRI measurements of cerebral deoxyhaemoglobin concentration $[\mathrm{dHb}]$ : correlation with near infrared spectroscopy (NIRS). NMR Biomed 1998;11:281-89

39. Baudelet C, Gallez B. How does blood oxygen level-dependent (BOLD) contrast correlate with oxygen partial pressure (pO2) inside tumors? Magn Reson Med 2002;48:980-86

40. Chopra S, Foltz WD, Milosevic MF, et al. Comparing oxygen-sensitive MRI (BOLD R2 ${ }^{\star}$ ) with oxygen electrode measurements: a pilot study in men with prostate cancer. Int J Radiat Biol 2009;85:805-13
41. Hoskin PJ, Carnell DM, Taylor NJ, et al. Hypoxia in prostate cancer: correlation of BOLD-MRI with pimonidazole immunohistochemistry-initial observations. Int $J$ Radiat Oncol Biol Phys 2007;68:1065-71

42. McPhail LD, Robinson SP. Intrinsic susceptibility MR imaging of chemically induced rat mammary tumors: relationship to histologic assessment of hypoxia and fibrosis. Radiology 2010;254:110-18

43. Rodrigues LM, Howe FA, Griffiths JR, et al. Tumor R2* is a prognostic indicator of acute radiotherapeutic response in rodent tumors. $J$ Magn Reson Imaging 2004;19:482-88

44. Losert C, Peller M, Schneider P, et al. Oxygen-enhanced MRI of the brain. Magn Reson Med 2002;48:271-77

45. Howe FA, Robinson SP, McIntyre DJ, et al. Issues in flow and oxygenation dependent contrast (FLOOD) imaging of tumours. NMR Biomed 2001;14:497-506

46. Hyder F, Kida I, Behar KL, et al. Quantitative functional imaging of the brain: towards mapping neuronal activity by BOLD fMRI. NMR Biomed 2001;14:413-31

47. Bulte D, Chiarelli P, Wise R, et al. Measurement of cerebral blood volume in humans using hyperoxic MRI contrast. J Magn Reson Imaging 2007;26:894-99

48. Jochimsen TH, Ivanov D, Ott DV, et al. Whole-brain mapping of venous vessel size in humans using the hypercapnia-induced BOLD effect. Neuroimage 2010;51:765-74

49. Santosh C, Brennan D, McCabe C, et al. Potential use of oxygen as a metabolic biosensor in combination with $\mathrm{T} 2{ }^{*}$-weighted MRI to define the ischemic penumbra. J Cereb Blood Flow Metab 2008:28:1742-53

50. Dani KA, Santosh C, Brennan D, et al. T2*-weighted magnetic resonance imaging with hyperoxia in acute ischemic stroke. Ann Neurol 2010;68:37-47

51. Mikulis DJ, Krolczyk G, Desal H, et al. Preoperative and postoperative mapping of cerebrovascular reactivity in Moyamoya disease by using blood oxygen level-dependent magnetic resonance imaging. J Neurosurg 2005; 103:347-55

52. Mandell DM, Han JS, Poublanc J, et al. Mapping cerebrovascular reactivity using blood oxygen level-dependent MRI in patients with arterial steno-occlusive disease: comparison with arterial spin labeling MRI. Stroke 2008;39:2021-28

53. Mandell DM, Han JS, Poublanc J, et al. Quantitative measurement of cerebrovascular reactivity by blood oxygen level-dependent MR imaging in patients with intracranial stenosis: preoperative cerebrovascular reactivity predicts the effect of extracranial-intracranial bypass surgery. AJNR Am J Neuroradiol 2011;32:721-27

54. Taylor NJ, Baddeley H, Goodchild KA, et al. BOLD MRI of human tumor oxygenation during carbogen breathing. J Magn Reson Imaging 2001;14:156-63

55. Al-Hallaq HA, River JN, Zamora M, et al. Correlation of magnetic resonance and oxygen microelectrode measurements of carbogeninduced changes in tumor oxygenation. Int J Radiat Oncol Biol Phys 1998;41:151-59

56. Dunn JF, O'Hara JA, Zaim-Wadghiri Y, et al. Changes in oxygenation of intracranial tumors with carbogen: a BOLD MRI and EPR oximetry study. J Magn Reson Imaging 2002;16:511-21

57. Zhao D, Jiang L, Hahn EW, et al. Comparison of $1 \mathrm{H}$ blood oxygen level-dependent (BOLD) and 19F MRI to investigate tumor oxygenation. Magn Reson Med 2009;62:357-64

58. Padhani AR, Krohn KA, Lewis JS, et al. Imaging oxygenation of human tumours. Eur Radiol 2007;17:861-72

59. O'Connor JP, Naish JH, Parker GJM, et al. Preliminary study of oxygen-enhanced longitudinal relaxation in MRI: a potential novel biomarker of oxygenation changes in solid tumors. Int J Radiat Oncol Biol Phys 2009;75:1209-15

60. O'Connor JPB, Naish JH, Jackson A, et al. Comparison of normal tissue $\mathbf{R} 1$ and $\mathbf{R}^{\star} 2$ modulation by oxygen and carbogen. Magn Reson Med 2009;61:75-83

61. Duyn JH, van Gelderen P, Li T-Q, et al. High-field MRI of brain 
cortical substructure based on signal phase. Proc Natl Acad Sci US A 2007;104:11796-801

62. Weisskoff RM, Kiihne S. MRI susceptometry: image-based measurement of absolute susceptibility of MR contrast agents and human blood. Magn Reson Med 1992;24:375-83

63. Fernández-Seara MA, Techawiboonwong A, Detre JA, et al. MR susceptometry for measuring global brain oxygen extraction. Magn Reson Med 2006;55:967-73

64. Haacke EM, Lai S, Reichenbach JR, et al. In vivo measurement of blood oxygen saturation using magnetic resonance imaging: a direct validation of the blood oxygen level-dependent concept in functional brain imaging. Hum Brain Mapp 1997;5:341-46

65. Bryant DJ, Payne JA, Firmin DN, et al. Measurement of flow with NMR imaging using a gradient pulse and phase difference technique. J Comput Assist Tomogr 1984;8:588-93

66. Jain V, Langham MC, Wehrli FW. MRI estimation of global brain oxygen consumption rate. $J$ Cereb Blood Flow Metab 2010;30:1598-607

67. Langham MC, Magland JF, Floyd TF, et al. Retrospective correction for induced magnetic field inhomogeneity in measurements of large-vessel hemoglobin oxygen saturation by MR susceptometry. Magn Reson Med 2009;61:626-33

68. Langham MC, Magland JF, Epstein CL, et al. Accuracy and precision of MR blood oximetry based on the long paramagnetic cylinder approximation of large vessels. Magn Reson Med 2009;62:333-40

69. Fan AP, Benner T, Bolar DS, et al. Phase-based regional oxygen metabolism (PROM) using MRI. Magn Reson Med 2012;67:669-78

70. Marques JP, Bowtell R. Application of a Fourier-based method for rapid calculation of field inhomogeneity due to spatial variation of magnetic susceptibility. Concepts Magn Reson 2005;25B:65-78

71. Koch KM, Papademetris X, Rothman DL, et al. Rapid calculations of susceptibility-induced magnetostatic field perturbations for in vivo magnetic resonance. Phys Med Biol 2006;51:6381-402

72. Shmueli K, de Zwart JA, van Gelderen P, et al. Magnetic susceptibility mapping of brain tissue in vivo using MRI phase data. Magn Reson Med 2009;62:1510-22

73. Wharton S, Schäfer A, Bowtell R. Susceptibility mapping in the human brain using threshold-based k-space division. Magn Reson Med 2010;63:1292-304

74. Liu T, Spincemaille P, de Rochefort L, et al. Calculation of susceptibility through multiple orientation sampling (COSMOS): a method for conditioning the inverse problem from measured magnetic field map to susceptibility source image in MRI. Magn Reson Med 2009;61:196-204

75. Wharton S, Bowtell R. Whole-brain susceptibility mapping at high field: a comparison of multiple- and single-orientation methods. Neuroimage 2010;53:515-25

76. de Rochefort L, Liu T, Kressler B, et al. Quantitative susceptibility map reconstruction from MR phase data using Bayesian regularization: validation and application to brain imaging. Magn Reson Med 2010;63:194-206

77. Li W, Wu B, Liu C. Quantitative susceptibility mapping of human brain reflects spatial variation in tissue composition. Neuroimage 2011;55:1645-56

78. Haacke EM, Tang J, Neelavalli J, et al. Susceptibility mapping as a means to visualize veins and quantify oxygen saturation. J Magn Reson Imaging 2010;32:663-76

79. Wright GA, Hu BS, Macovski A. 1991 I.I. Rabi Award: estimating oxygen saturation of blood in vivo with MR imaging at $1.5 \mathrm{~T}$. J Magn Reson Imaging 1991;1:275-83

80. Golay X, Silvennoinen MJ, Zhou J, et al. Measurement of tissue oxygen extraction ratios from venous blood $\mathrm{T}(2)$ : increased precision and validation of principle. Magn Reson Med 2001;46:282-91

81. van Zijl PC, Eleff SM, Ulatowski JA, et al. Quantitative assessment of blood flow, blood volume and blood oxygenation effects in functional magnetic resonance imaging. Nat Med 1998;4:159-67

82. Oja JM, Gillen JS, Kauppinen RA, et al. Determination of oxygen extraction ratios by magnetic resonance imaging. J Cereb Blood Flow Metab 1999;19:1289-95

83. $\mathrm{Lu} \mathrm{H}, \mathrm{Xu} F$, Grgac K, et al. Calibration and validation of TRUST MRI for the estimation of cerebral blood oxygenation. Magn Reson Med 2012;67:42-49

84. $\mathrm{Lu} \mathrm{H}, \mathrm{Ge} \mathrm{Y}$. Quantitative evaluation of oxygenation in venous vessels using T2-Relaxation-Under-Spin-Tagging MRI. Magn Reson Med 2008;60:357-63

85. Buxton R. Introduction to Functional Magnetic Resonance Imaging. New York: Cambridge University Press; 2002

86. Xu F, Ge Y, Lu H. Noninvasive quantification of whole-brain cerebral metabolic rate of oxygen (CMRO2) by MRI. Magn Reson Med 2009;62:141-48

87. Bolar DS, Rosen BR, Sorensen AG, et al. QUantitative Imaging of eXtraction of oxygen and TIssue consumption (QUIXOTIC) using venular-targeted velocity-selective spin labeling. Magn Reson Med 2011;66:1550-62

88. Wong EC, Cronin M, Wu WC, et al. Velocity-selective arterial spin labeling. Magn Reson Med 2006;55:1334-41

89. Christen T, Zaharchuk G, Pannetier N, et al. Quantitative MR estimates of blood oxygenation based on $\mathrm{T}^{\star}$ : a numerical study of the impact of model assumptions. Magn Reson Med 2011 Dec 19. [Epub ahead of print] 